\title{
A novel balloon-attached endoscopy-assisted reduction technique for an acute strangulated stoma prolapse
}

Stoma prolapse is a common late complication that occurs in $2-26 \%$ of colostomies [1]. Prolapse is most frequently seen after loop colostomies [2] and often involves the distal limb [3]. Prolapsed stoma is rarely incarcerated or strangulated; however, such cases require emergency surgery $[3,4]$.

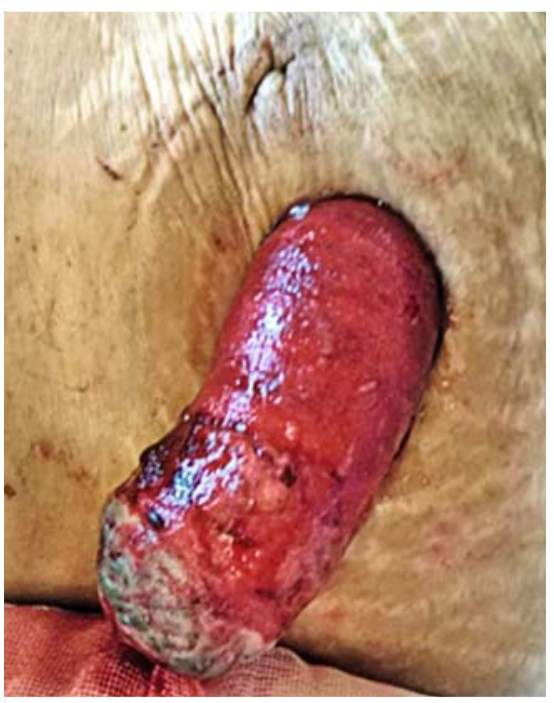

- Fig. 1 Stoma prolapse.
A 70-year-old woman suffering from obstructive rectal cancer with multiple liver and lung metastases underwent transverse loop colostomy and subsequent chemotherapy. On day 2 after initiation of second-line chemotherapy (infusional 5-FU, leucovorin, and irinotecan plus ramucirumab), the distal limb of loop colostomy was prolapsed and strangulated owing to edema. The prolapsed colon wall was entirely reddish and edematous with a superficial brown spot at the tip ( $\triangleright$ Fig.1) and manual reduction using sugar as a desiccant was unsuccessful. Although emergency surgery is usually indicated in such circumstances, it is associated with perioperative complications due to administration of ramucirumab. Hence, we attempted a unique balloon-attached endoscopy-assisted reduction ( $>$ Fig.2). An 11-mm balloon for endoscopic injection sclerotherapy (MD47411L; Sumitomo Bakelite Co., Ltd., Tokyo, Japan) was attached to the shaft of the colonoscope ( $>$ Fig. 3 ), and it was inserted into the prolapsed stoma such that the balloon came in contact with the invaginated inside wall. To ensure secure placement, the balloon diameter should be smaller than the outer diameter of the prolapsed tract but slightly larger than the inside diameter. The balloon was kept in contact with the prolapsed inside wall while the endoscope was gradually pushed forward, and simultaneously another operator facilitated repositioning of the inside wall with their hand. This procedure was slowly repeated until the prolapsed stoma had been successfully reduced (> Fig.4). No recurrence was observed thereafter.

We describe a novel non-surgical "balloon-attached endoscopy-assisted reduction" approach that may be a useful conservative technique for reducing an incarcerated stoma prolapse ( $\vee$ Video 1$)$.

\section{Endoscopy_UCTN_Code_TTT_1AT_2AF}

\section{Competing interests}

The authors declare that they have no conflict of interest.

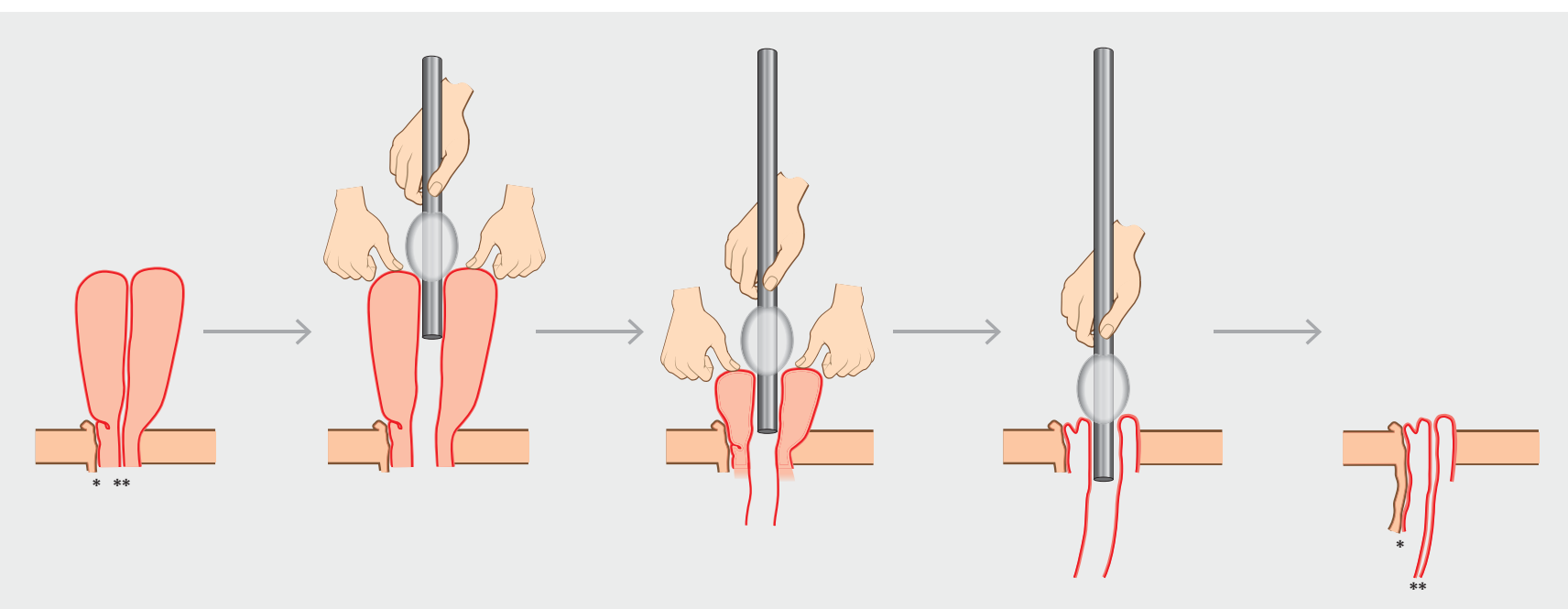

- Fig. 2 Schema of balloon-attached endoscopy-assisted reduction ( ${ }^{*}$ proximal limb, ${ }^{* *}$ distal limb). 


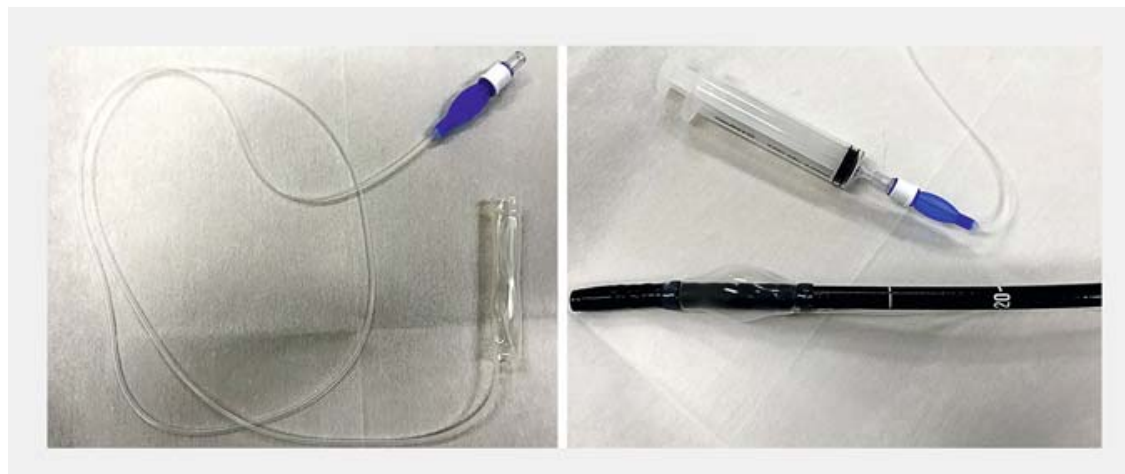

- Fig. 3 Balloon-attached endoscopy. Balloon for endoscopic injection sclerotherapy was attached to the shaft of the colonoscope.

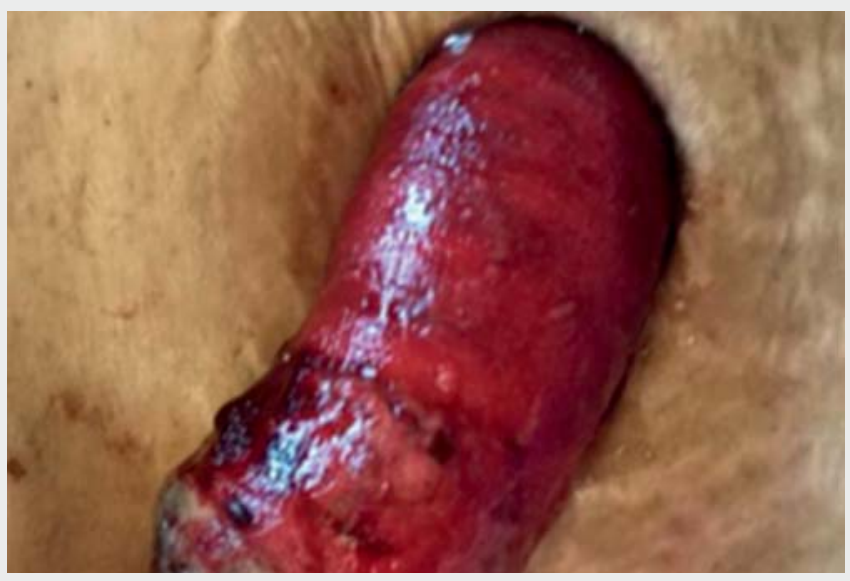

Video 1 Balloon-attached endoscopy-assisted reduction for strangulated stoma prolapse.

\section{The authors}

Takaya Shimura ${ }^{1}$, Takanori Ozeki ${ }^{1}$, Hajime Ushigome $^{2}$, Takahisa Hirokawa ${ }^{2}$, Kazuyoshi Shiga $^{2}$, Hiroki Takahashi ${ }^{2}$, Hiromi Kataoka ${ }^{1}$

1 Department of Gastroenterology and Metabolism, Nagoya City University Graduate School of Medical Sciences, Japan

2 Department of Gastroenterological Surgery, Nagoya City University Graduate School of Medical Sciences, Japan

\section{Corresponding author}

Takaya Shimura, MD, PhD

Department of Gastroenterology and Metabolism, Nagoya City University Graduate School of Medical Sciences, 1 Kawasumi, Mizuho-cho, Mizuho-ku, Nagoya
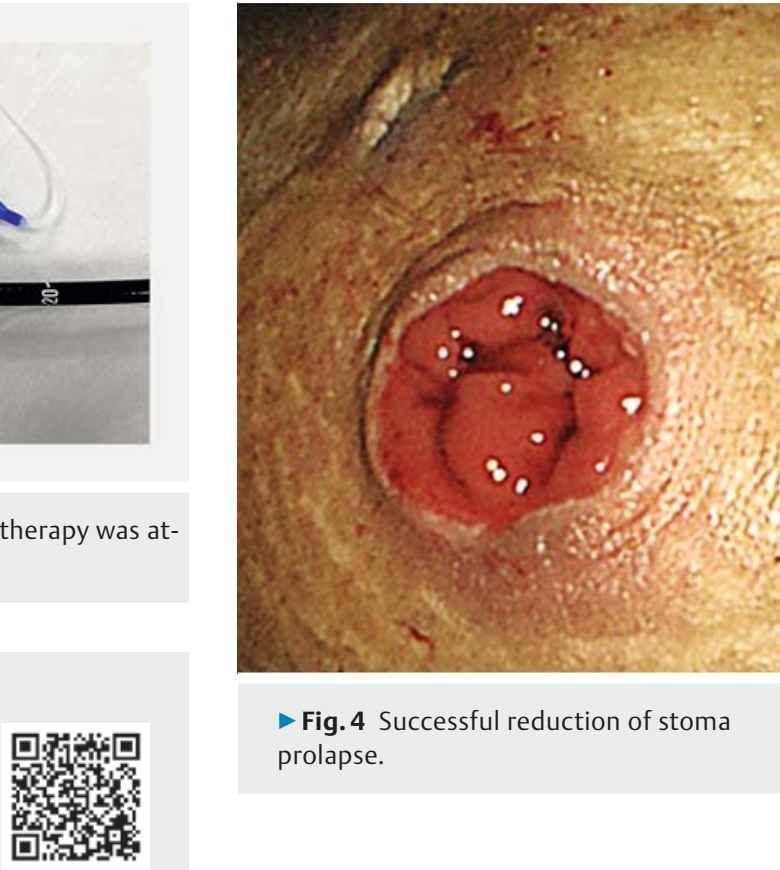

Fig. 4 Successful reduction of stoma prolapse.

\section{Bibliography}

Endoscopy 2022; 54: E36-E37

DOI 10.1055/a-1346-8427

ISSN 0013-726X

published online 19.2.2021

(c) 2021. Thieme. All rights reserved.

Georg Thieme Verlag KG, Rüdigerstraße 14, 70469 Stuttgart, Germany

\section{ENDOSCOPY E-VIDEOS}

https://eref.thieme.de/e-videos

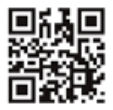

Endoscopy E-Videos is a free access online section, reporting on interesting cases and new

Fax: +81-52-852-0952

tshimura@med.nagoya-cu.ac.jp

\section{References}

[1] Husain SG, Cataldo TE. Late stomal complications. Clin Colon Rectal Surg 2008; 21: $31-40$

[2] Jayarajah U, Samarasekara AM, Samarasekera DN. A study of long-term complications associated with enteral ostomy and their contributory factors. BMC Res Notes 2016; 9: 500

[3] Krishnamurty DM, Blatnik J, Mutch M. Stoma Complications. Clin Colon Rectal Surg 2017; 30: 193-200

[4] Mittal R, Jalouta T, Luchtefeld M et al. Surgical management of stomal prolapse - Is there a superior approach to repair? Am J Surg 2020; 220: 1010-1014
This section has its own submission website at

https://mc.manuscriptcentral.com/e-videos 